\title{
Variation in Scheduling and Receipt of Primary Care Follow-up After Hospitalization for COVID-19 in Michigan
}

J Gen Intern Med 36(11):3654-6 DOI: $10.1007 / \mathrm{s} 11606-021-07116-6$

This is a U.S. government work and not under copyright protection in the U.S.; foreign copyright protection may apply 2021

$\mathrm{P}$ atients hospitalized for coronavirus disease (COVID-19) commonly experience new or worsened systemic or cardiopulmonary symptoms, such as fatigue, dyspnea, and weakness ${ }^{1}$. These symptoms may persist for weeks, limit the return to normal activities ${ }^{2}$, and contribute to re-hospitalization ${ }^{3}$. In May 2020, the term "long COVID" was coined to describe the life-altering impacts of COVID-19 ${ }^{4}$.

Timely outpatient follow-up has been promoted as a key strategy to reduce readmission and promote recovery after acute illness but does not occur consistently ${ }^{2,5}$. In this study, we examined the variation in primary care scheduling and follow-up across hospitals in Michigan during March-December 2020.

\section{METHODS}

This is an observational cohort study of patients discharged alive from hospitalization for COVID-19 at 38 hospitals in the MI-COVID19 initiative during COVID waves 1 (March-August 2020) and 2 (October-December 2020). Professional abstractors collected data from patient medical records using structured templates $^{2}$. Additionally, patients hospitalized during wave 1 were contacted by telephone to complete a 60-day post-discharge survey that included questions about follow-up care ${ }^{2}$. Measures of interest were scheduling of primary care follow-up prior to discharge and receipt of primary care follow-up within 14 and 30 days of discharge (by telephone, videoconference, or in-person visit). We also examined variation in follow-up practices across hospitals and by hospital type. This study was deemed exempt by the University of Michigan IRB (HUM00179611).

Received July 9, 2021

Accepted August 25, 2021

Published online September 14, 2021
RESULTS

Among 1839 patients discharged alive after hospitalization for COVID-19 during wave 1, scheduling of follow-up prior to discharge was rare. Overall, only $9.0 \%$ (166/1839) of patients discharge alive were scheduled for 14-day follow-up and $10.8 \%$ (198/1839) for 30-day follow-up. Scheduling varied markedly across hospitals (Fig. 1A). In sensitivity analyses excluding patients discharged to post-acute care facilities, findings were similar.

Among 683 patients completing the post-hospitalization survey, $53.4 \%(365 / 683)$ had primary care follow-up within 14 days, and $71.3 \%$ (487/683) within 30 days of discharge. Follow-up varied across hospitals, ranging from 17.9 to $81.8 \%$ for 14-day and 40.0 to $91.7 \%$ for 30-day follow-up (Fig. 1B). Receipt of 14-day follow-up was more common among patients scheduled for 14-day follow-up prior to discharge (66.7\% (44/66) vs $52.0 \%$ (321/617), $p=0.023)$, but receipt of 30 -day follow-up did not differ by scheduling $(80.0 \%(60 / 75)$ vs $70.2 \%$ (427/608), $p=0.078)$.

During wave 2 , scheduling of primary care follow-up increased but still occurred for only a minority of patients. A total of $23.8 \%$ (258/1083) had 14-day and 25.3\% (274/1083) 30-day follow-up scheduled prior to discharge. Variation in scheduling persisted across hospitals (Fig. 1C).

Across waves 1 and 2, scheduled follow-up was higher among patients discharged from non-profit versus for-profit hospitals but similar for patients discharged from teaching versus non-teaching hospitals (Table 1).

\section{DISCUSSION}

In this multi-hospital cohort of patients hospitalized for COVID-19 in Michigan, there was marked variation in primary care follow-up. Two-week follow-up varied more than 4-fold across hospitals during wave 1, and fewer than $10 \%$ of the patients were scheduled for a 14-day follow-up prior to discharge. During wave 2, 25\% were scheduled for a 14-day follow-up prior to discharge, but hospital-level variation persisted. At the extremes, four hospitals scheduled no follow-up, while one hospital scheduled follow-up for $>90 \%$ of patients.

Outpatient follow-up visits are a key opportunity to screen for, acknowledge, and address the multi-faceted symptoms after COVID-19 ${ }^{1}$ and other acute illnesses. While the long- 


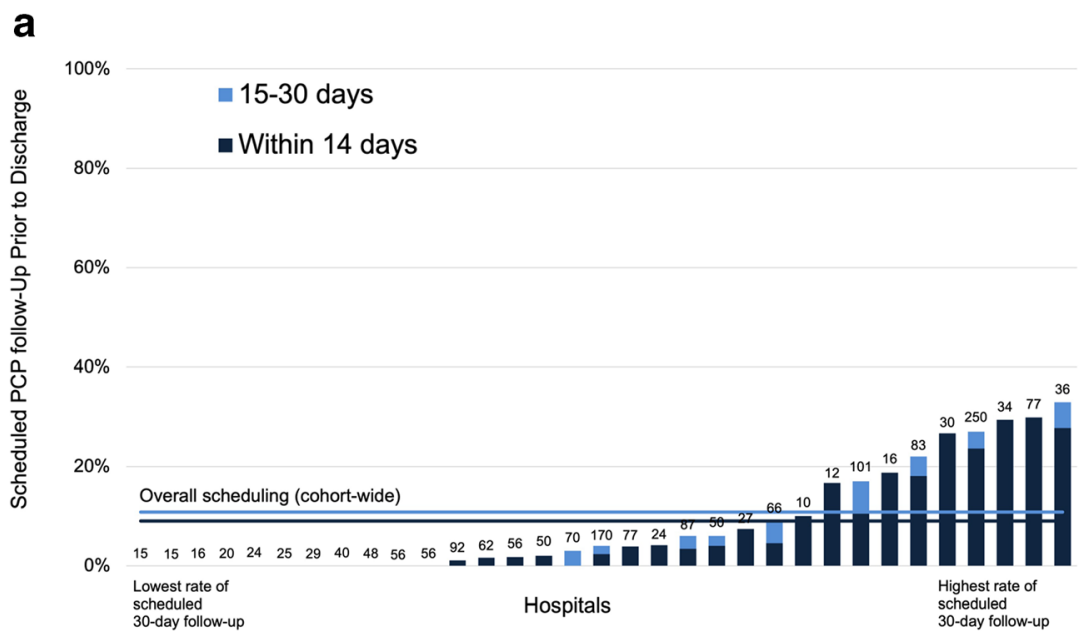

b
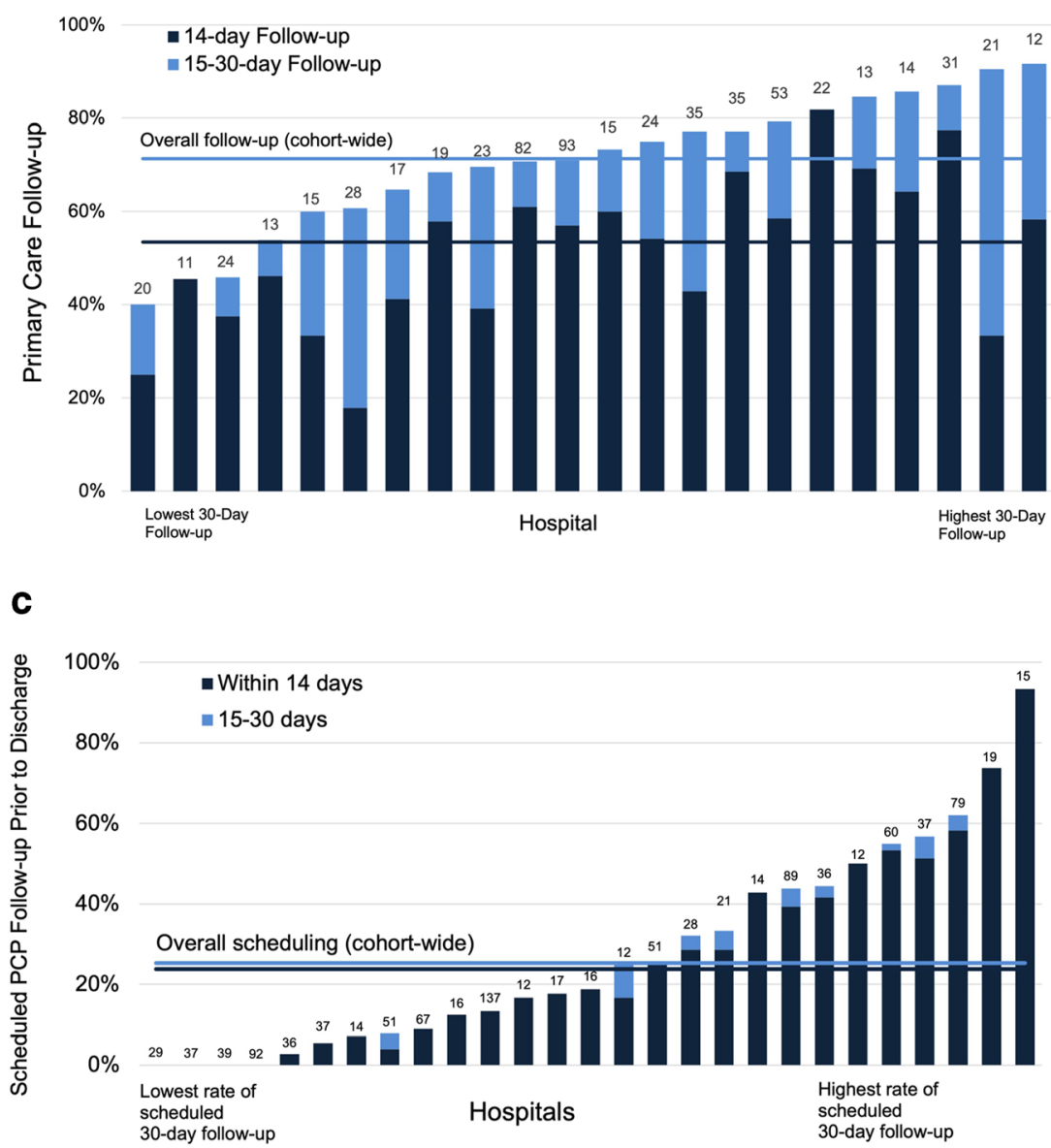

Figure 1 Variation in scheduling and receipt of primary care follow-up across hospitals. Panel A Variation in scheduled primary care follow-up across hospitals during wave 1. Primary care follow-up scheduled prior to discharge, to occur within 14 days (navy) and 15-30 days (royal), by the hospital ( $N=33$ hospitals; 1824 patients). Each bar represents one hospital; the number of patients per hospital is shown above each bar. Hospitals with fewer than 10 eligible patients are not shown ( $N=4$ hospitals; 15 patients). Navy and royal horizontal lines depict the overall proportion of hospitalizations with scheduled 14-day and 30-day follow-up, respectively, prior to discharge. Panel B Variation in receipt of primary care follow-up by the hospital during wave 1 Primary care follow-up within 14 days (navy) and 30 days (royal) of hospital discharge, by hospitals $(N=22$ hospitals; 620 patients). Each bar represents one hospital; the number of patients per hospital is shown above each bar. Hospitals with fewer than 10 patients completing telephone follow-up are not shown ( $N=13$ hospitals; 63 patients). Navy and royal horizontal lines depict the overall proportion of hospitalizations with 14-day and 30-day follow-up, respectively. Panel C Variation in scheduled primary care follow-up across hospitals during wave 2. Primary care follow-up scheduled prior to discharge to occur within 14 days (navy) and 15-30 days (royal), and at any point (light blue), by the hospital ( $N=27$ hospitals; 1063 patients). Each bar represents one hospital; the number of patients per hospital is shown above each bar. Hospitals with fewer than 10 eligible patients are not shown ( $N=4$ hospitals; 20 patients). Navy and royal horizontal lines depict the overall proportion of hospitalizations with 14-day and 30-day follow-up, respectively. 
Table 1 Proportion of Patients with Primary Care Follow-up Scheduled Prior to Discharge by Wave and Hospital Type

\begin{tabular}{llll}
\hline \hline & Number & & \\
\cline { 3 - 4 } & & $\begin{array}{l}\text { Within 14 } \\
\text { days }\end{array}$ & $\begin{array}{l}\text { Within 30 } \\
\text { days }\end{array}$ \\
\hline $\begin{array}{l}\text { Total wave 1 live } \\
\text { discharges }\end{array}$ & 1839 & $9.0 \%$ & $10.8 \%$ \\
$\begin{array}{l}\text { Discharged from a } \\
\text { teaching hospital }\end{array}$ & 1667 & $8.9 \%$ & $10.5 \%$ \\
$\begin{array}{l}\text { Discharged from non- } \\
\text { teaching hospital }\end{array}$ & 172 & $10.5 \%$ & $13.4 \%$ \\
$\begin{array}{l}\text { Discharged from non- } \\
\text { profit hospital }\end{array}$ & 1738 & $9.4 \%$ & $11.2 \%$ \\
$\begin{array}{l}\text { Discharged from } \\
\text { proprietary hospital }\end{array}$ & 101 & $2.0 \%$ & $4.0 \%$ \\
$\begin{array}{l}\text { Total wave 2 live } \\
\text { discharges }\end{array}$ & 1083 & $23.8 \%$ & $25.3 \%$ \\
$\begin{array}{l}\text { Discharged from a } \\
\text { teaching hospital }\end{array}$ & 975 & $24.2 \%$ & $25.6 \%$ \\
$\begin{array}{c}\text { Discharged from non- } \\
\text { teaching hospital }\end{array}$ & 108 & $20.4 \%$ & $22.2 \%$ \\
$\begin{array}{c}\text { Discharged from non- } \\
\text { profit hospital }\end{array}$ & 1008 & $25.1 \%$ & $26.7 \%$ \\
$\begin{array}{l}\text { Discharged from } \\
\text { proprietary hospital }\end{array}$ & 75 & $6.7 \%$ & $6.7 \%$ \\
\hline
\end{tabular}

Data on hospital ownership status were obtained from data.medicare. gov; Hospital General Information. Retrieved from 06/03/2020 from https://data.medicare.gov/widgets/xubh-q36u

term sequelae of COVID-19 were not well-known until wave 2, 2-week follow-up is encouraged by the Centers for Medicare and Medicaid Services and may accelerate evaluation and management of problematic symptoms (e.g., functional impairments) after hospitalization. Thus, while our data are specific to COVID-19 hospitalization, they also reflect a broader issue of care fragmentation and poor transition from hospital to primary care ${ }^{6}$.

Limitations of this study include ascertainment of primary care scheduling and visits from the medical record and patients' self-report, respectively. Furthermore, receipt of primary care follow-up was measured among a subset of patients who completed a telephone survey. The response rate to this survey was low (42.7\%), but demographics and illness severity were similar among respondents versus non-respondents.

This study highlights the incomplete scheduling and receipt of primary care follow-up after COVID-19 hospitalization, as well as marked variation in scheduling practices across hospitals. The reasons for this hospital variation are unclear and warrant further exploration. Enhanced policies and programs to facilitate post-hospitalization follow-up appear necessary.

Acknowledgments: The authors thank all the BCBSM Collaborative Quality Initiatives that partnered on data collection, all hospitals that volunteered to be part of the MI-COVID19 Initiative, Elizabeth McLaughlin, Jennifer Horowitz, and Tae Kim for project management. This manuscript does not represent the views of the Department of Veterans Affairs or the US government. This material is the result of work supported with resources and the use of facilities at the Ann Arbor VA Medical Center.

Hallie C. Prescott, $M D, M S C^{1,2}$

Bonnie Cheng, $\mathrm{MPH}^{3}$

Chelsea Abshire, $M P H^{3}$
Megan O'Malley, $P h D^{1}$

Scott A. Flanders, $M D^{1}$

Renuka Tipirneni, $M D, M^{1} c^{1}$

Vineet Chopra, $\mathrm{MD}, \mathrm{MSc}^{1}$

${ }^{1}$ Department of Medicine, University of Michigan,

Ann Arbor, MI, USA

${ }^{2}$ VA Center for Clinical Management Research,

Ann Arbor, MI, USA

${ }^{3}$ Michigan Value Collaborative,

Ann Arbor, MI, USA

Corresponding Author: Hallie C. Prescott, MD, MSc; Department of Medicine, University of Michigan, Ann Arbor, MI, USA (e-mail: hprescot@med.umich.edu).

Funding This study received financial support from Blue Cross Blue Shield of Michigan and Blue Care Network as part of the BCBSM Value Partnerships Program, the Michigan Public Health Institute, and the Michigan Department of Health \& Human Services.

\section{Declarations:}

Conflict of Interest: The authors have no financial conflicts of interest. They report funding from NIH, VA HSR\&D, and AHRQ outside of the study. Dr. Prescott serves on the Surviving Sepsis Campaign Guidelines panels for sepsis and COVID-19.

Open Access This article is licensed under a Creative Commons Attribution 4.0 International License, which permits use, sharing, adaptation, distribution and reproduction in any medium or format, as long as you give appropriate credit to the original author(s) and the source, provide a link to the Creative Commons licence, and indicate if changes were made. The images or other third party material in this article are included in the article's Creative Commons licence, unless indicated otherwise in a credit line to the material. If material is not included in the article's Creative Commons licence and your intended use is not permitted by statutory regulation or exceeds the permitted use, you will need to obtain permission directly from the copyright holder. To view a copy of this licence, visit http://creativecommons. org/licenses/by/4.0/.

\section{REFERENCES}

1. Prescott HC. Outcomes for Patients Following Hospitalization for COVID19. JAMA. 2021

2. Chopra V, Flanders SA, O'Malley M, Malani AN, Prescott HC. Sixty-Day Outcomes Among Patients Hospitalized With COVID-19. Ann Intern Med. 2020.

3. Donnelly JP, Wang XQ, Iwashyna TJ, Prescott HC. Readmission and Death After Initial Hospital Discharge Among Patients With COVID-19 in a Large Multihospital System. JAMA. 2021;325(3):304-306.

4. Perego E, Callard F, Stras L, Melville-Jóhannesson B, Pope R, Alwan NA. Why we need to keep using the patient made term "Long Covid". The BMJ Opinion Web site. https://blogs.bmj.com/bmj/2020/10/01/whywe-need-to-keep-using-the-patient-made-term-long-covid/. Published 2020. Accessed March 1, 2021.

5. Misky GJ, Wald HL, Coleman EA. Post-hospitalization transitions: Examining the effects of timing of primary care provider follow-up. $J$ Hosp Med. 2010;5(7):392-397.

6. Jones CD, Vu MB, O'Donnell CM, et al. A failure to communicate: a qualitative exploration of care coordination between hospitalists and primary care providers around patient hospitalizations. J Gen Intern Med. 2015;30(4):417-424.

Publisher's Note: Springer Nature remains neutral with regard to jurisdictional claims in published maps and institutional affiliations. 